\title{
Effectiveness of psychosocial interventions in abused children and their families
}

\author{
Firoozeh Derakhshanpour ${ }^{1}$, Ahmad Hajebi ${ }^{2 *}$, Leili Panaghi ${ }^{3}$, Zohre Ahmadabadi ${ }^{4}$ \\ Received: 15 Dec 2016 \\ Published: 30 Aug 2017
}

\begin{abstract}
Background: Child abuse is a significant public health and social problem worldwide. It can be described as a failure to provide care and protection for children by the parents or other caregivers. This study aimed at evaluating the effectiveness of psychosocial interventions in abused children and their families.

Methods: This quasi-experimental study was conducted in the psychosocial support unit of a pediatric hospital in Bandar Abbas, Iran, from 2012 to 2013. The participants consisted of child abuse cases and their parents who referred to the psychosocial support unit to receive services. Services delivered in this unit included parenting skills training, psychiatric treatments, and supportive services. The effectiveness of the interventions was assessed with Child Abuse Questionnaire, General Health Questionnaire (GHQ), and Strengths and Difficulties Questionnaires (SDQ). Participants were assessed at baseline, at 3, and 6 months follow-ups. ANOVA with repeated measures and Friedman test were used to evaluate the effect of the interventions.

Results: A total of 68 children and their parents enrolled in this study, of whom 53\% were males. Post-intervention follow-ups revealed significant changes in mothers' general health questionnaire $(p<0.001)$, and children's conduct problem $(p<0.05)$, hyperactivity $(\mathrm{p}<0.001)$, and peer problems $(\mathrm{p}<0.05)$. Physical and emotional abuses significantly decreased $(\mathrm{p}<0.001)$.

Conclusion: Our findings revealed that psychosocial interventions effectively improved child-parents interaction and mental health of parents. The effectiveness of interventions based on subgroup analysis and implications of the results have been discussed for further development of psychosocial interventions in the health system.
\end{abstract}

Keywords: Child Abuse, Neglected, Psychosocial Intervention, Parenting Skills Training

Copyright $\odot$ Iran University of Medical Sciences

Cite this article as: Derakhshanpour F, Hajebi A, Panaghi L, Ahmadabadi Z. Effectiveness of psychosocial interventions in abused children and their families. Med J Islam Repub Iran. 2017 (30 Aug);31:49. https://doi.org/10.14196/mjiri.31.49

\section{Introduction}

Evidence shows that child abuse, as a health problem in Iranian families, needs to be addressed $(1,2)$. According to the ecological models of child development (3), definition of child abuse as a multifaceted problem requires a context to explain all the influential factors in a systematic approach (4-6) and address the risk factors and multiple support factors at individual, familial and, social levels and their interaction (7).

At the individual level, children's characteristics, name-

Corresponding author:Dr Ahmad Hajebi, hajebi.ahmad@gmail.com

1. Psychiatric Department, Golestan University of Medical Sciences, Gorgan, Iran.

2. Research Center for Addiction \& Risky Behaviors (ReCARB), Psychiatric Department, Iran University of Medical Sciences, Tehran, Iran.

3. Family Research Institute, Shahid Beheshti University, Tehran, Iran.

4. School of Public Health, University of Queensland, Brisbane, Australia. ly, behavioral problems, physical aggression, antisocial behaviors, poor emotional adjustment, distraction, negative emotions, difficult temperament, developmental retardation, and physical disabilities (8-14); at the familial level, deficits in parenting skills, and wrong parenting attitudes $(15,16)$, mental health problems of the parents, ie, depression and stress (7, 17-21), addiction, and substance abuse $(22,23)$; and at a larger perspective, the living status including economic and social status $(24,25)$,

$\uparrow$ What is "already known" in this topic:

- Psychosocial interventions effectively improved child-parents interaction and mental health of parents

- In child abuse interventions family is considered as a single unit and could have an effective role in service provision.

- Providing multi-level programs are more effective for preventing child abuse.

$\rightarrow$ What this article adds:

Establishment of a child support unit in a hospital for providing multi-level interventions for abused children and their parents is an efficient and feasible model for child abuse management. 
lack of social support networks, and local communication (26) are among the main risk factors of child abuse.

Child abuse risk factors are targeted and addressed in interventional programs, particularly family interventions (27). In the literature on child abuse prevention, the role of family interventions in this respect has been greatly emphasized (16, 28-30). Evidence shows that programs focusing on a combination of changing attitudes, enhancing knowledge, and parenting skills are more effective than programs focusing on just one parameter (31). In addition, the more successful programs are those that include group trainings, personal counseling, and house visits at the same time (32-34).

Although child abuse commonly occurs in the Iranian families, most children and their parents do not receive adequate and efficient support $(1,35)$. The organizations providing services to abused children in Iran such as the Ministry of Health, the Welfare Organization, and the Imam Khomeini Relief Foundation are not coordinated with each other, and this decreases the efficacy of their services. To overcome this problem and fill the gap among these organizations and their services, some interventions were designed and implemented from the diagnosis level to different therapeutic and supportive services. Considering the ecological approach and the complex nature of child abuse, this study aimed at designing an efficient and feasible intervention model. The primary outcome measure in this study was reducing the frequency of child abuse, and the secondary outcome measure was improving mental health of parents and decreasing the problems of children.

\section{Methods}

\section{Study Design}

This prospective quasi-experimental pilot study was conducted to design and establish a child support unit in a hospital, and its chief objective was to provide an efficient and feasible intervention model and assess its effectiveness for abused children and their families.

\section{Participants}

The target populations were the abused children and their families in a pediatric hospital in Bandar Abbas, Iran, from 2012 to 2013 who referred to the psychosocial support unit, a specialty unit providing psychosocial support services for the referred patients. In this study, child abuse included physical, emotional, and sexual abuse. Sample size was calculated to be 50 assuming alpha $=0.05$, beta $=$ 0.2 , study power of $80 \%$, and impact size of 4 . To compensate for the possible dropouts or loss to follow up, 68 participants were included.

The inclusion criteria included children residing in Bandar Abbas, who were diagnosed as cases of child abuse by the physicians, and their parents were cooperative and consented to their participation in the study. The exclusion criteria were abused children whose parents did not consent to their participation in the study, those residing in other cities, and those who could not be accessed.

\section{Assessment Tools}

The following tools were used in the present study:

1. Demographic Questionnaire: This questionnaire included data about the child and parents such as gender, living status, order of child in the family, parents' marital status, occupational status, education level, age, history of substance abuse, and history of mental disorders in parents.

2. Child Abuse Checklist: This checklist was designed by Arabgol et al. (35) using the World Health Organization's definition of violence and taking into account various forms of child abuse. This checklist evaluates all forms of child abuse as follows: physical, emotional, and sexual abuse.

3. Child's Strengths and Difficulties Questionnaire (SDQ): This questionnaire is a short screening tool with 25 phrases. Each question can be answered with "certainly true", "somewhat true", and "not true" options and evaluates 5 major subgroups of psychological symptoms: conduct problems, hyperactivity, emotional symptoms, peer problems, and prosocial behavior. The sum of the first 4 subgroups comprises the total score of difficulties (36, 37). Tehranidoost et al. (38) evaluated this questionnaire in an Iranian population and its sensitivity was calculated to be $74 \%$.

4. General Health Questionnaire (GHQ): The 28question General Health Questionnaire (GHQ-28) was designed by Goldberg \& Hillier (1979) by factor analysis of its longer version. This questionnaire contains questions assessing the individual's mental status in the past 1 month and includes signs, namely, abnormal thoughts and feelings, and aspects of observable behaviors emphasizing the present situation. This questionnaire has the ability to measure various aspects of mental health such as physical manifestations, anxiety, insomnia, and depression. The total score of an individual is obtained by summing the 4 subscale scores. For scoring, each answer from right to left is allocated a score of $0,1,2$, or 3. Ebrahimi et al. (2007) reported the cut-off point of 24 for this questionnaire, with sensitivity of $80 \%$ and specificity of $99 \%$ at this point. The split-half reliability coefficient and Cronbach's alpha were 90\%, and 97\%, respectively, in their study.

\section{Procedure}

First, all the personnel and attending physicians in the departments and emergency ward of the pediatric hospital attended the training workshops on how to detect cases of child abuse. They were requested to look for such cases in their routine daily activities, and in case of finding a case of child abuse, report the case to psychosocial support units for abused children for further scrutiny (Table 1).

Children referred to the psychosocial support unit were first visited by a psychologist with adequate experience in recognizing abused children.

In the next step, the abused child and his/her parents were examined and visited by a psychiatrist. If the psychiatrist diagnosed that the child or parents required pharmaceutical therapy, the therapeutic intervention was started and the next session for continuation of medical treatment 
Table 1. Interventions* for Abused Children and Their Parents

\begin{tabular}{|c|c|c|c|}
\hline Target Group & Child Intervention & Target Group & Parents' Intervention \\
\hline $\begin{array}{l}\text { Children with mental disorders } \\
\text { diagnosed by a psychiatrist }\end{array}$ & Treatment of mental disorder & $\begin{array}{l}\text { Parents with mental disorders } \\
\text { diagnosed by a psychiatrist }\end{array}$ & Treatment of mental disorder \\
\hline $\begin{array}{l}\text { Children with physical problems } \\
\text { diagnosed by a pediatrician }\end{array}$ & Medical intervention & Parents with substance abuse & Substance abuse treatment \\
\hline $\begin{array}{l}\text { Children with malnutrition diagnosed } \\
\text { by a pediatrician }\end{array}$ & Nutritional intervention & All parents & $\begin{array}{c}\text { Parenting skills training \& Anger } \\
\text { management training }\end{array}$ \\
\hline
\end{tabular}

was scheduled. Then, the child and parents were referred to a psychologist or a social worker for nonphamaceutical interventions. Nearly all the parents participated in parenting skills training and anger management courses. In addition, the children participated in a training course for learning how to protect themselves from child abuse and to be prepared for everyday life, however, some of the parents were resistant against this activity. Other nonpharmaceutical therapies, specifically social and legal support, were performed based on the requirements of children or their parents. These interventions included counseling services, school counseling, financial support through welfare organizations, or charity foundations, home visit etc. Social workers referred children and their parents to support services if necessary. If the living status of the patients had to be evaluated, or in case of parents not showing up for treatment, home visits were performed. If the child's life was in danger, social workers requested legal support for the child. Parenting skills were taught to parents in 6 sessions. These sessions were held based on the principles of constructive training with the difference that 2 of the 6 sessions were allocated to anger management and discussions on child abuse, physical punishment, and its negative effects on the child.

\section{Data Collection}

After establishing a connection with the children and their parents, Child Abuse Questionnaire was filled out based on the collected data (through observing, examining, and interviewing the parents and children). Experience shows that most abusive parents hide abusing their children, thus, for data collection, it is very important for the counselor to establish a connection with them and encourage them to open up. Child's Strengths and Difficulties Questionnaire was then filled out for the child based on the obtained data from the parents. General Health Questionnaire was filled out for the mothers. The participants received services and were followed- up after 3 and 6 months. These questionnaires were completed by the psychologist of the team who had participated in an educational workshop (the workshop on Child Abuse Detection and Acquaintance with the Instruments), and had adequate clinical experience for making a connection with the children and parents.

Study design and objectives were thoroughly explained to the parents and older children (adolescents); and after obtaining written informed consent, they were entered the study.

\section{Data Analysis}

Data were analyzed using SPSS 18 software. Demographic characteristics of the participants were expressed as frequency, percentage, mean, and standard deviation. ANOVA was used to assess the effect of interventions on the child's strengths and difficulties and mothers' mental health. To eliminate the possible effects of mother education, this variable was entered into the covariance test as a covariate. Bonferroni post hoc test was then used to assess the differences between the mean values in the 3 stages. To evaluate the effect of interventions on physical and emotional child abuse (ordinal scale), nonparametric Friedman test was used. $\mathrm{P}<0.05$ was considered statistically significant.

\section{Results}

As shown in the participants' flow diagram (Fig. 1), out of 130 cases referred to the center, a total of 78 cases of child abuse were detected; out of which, 10 did not consent to participate in the study. The remaining 68 were entered into the study; and 4 were excluded prior to the first assessment (at 3 months), and 7 were excluded prior to the second assessment (at 6 months). A total of 68 cases were evaluated. Tables 2 and 3 present the demographic characteristics of the children and their parents.

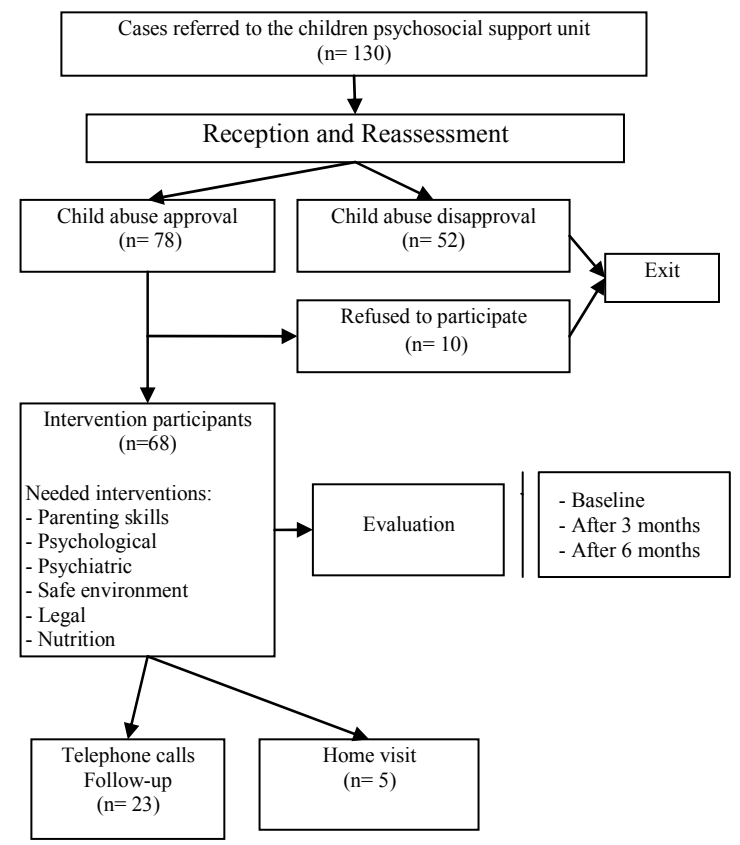

Fig. 1. Flow of the Participants during the Study 


\begin{tabular}{|c|c|}
\hline Variables & $\mathrm{n}(\%)$ \\
\hline \multicolumn{2}{|l|}{ Gender } \\
\hline Male & $26(52.9)$ \\
\hline Female & $32(47.1)$ \\
\hline \multicolumn{2}{|l|}{ Child's age } \\
\hline Younger than 2 yrs. & $13(19.1)$ \\
\hline $2-4$ yrs. & $15(22.1)$ \\
\hline $4-6$ yrs. & $27(39.7)$ \\
\hline Older than 6 yrs. & $13(19.1)$ \\
\hline \multicolumn{2}{|l|}{ Child's order } \\
\hline First & $45(66.2)$ \\
\hline Second & $13(19.1)$ \\
\hline Third or higher & $10(14.7)$ \\
\hline \multicolumn{2}{|l|}{ Living status } \\
\hline Both parents & $66(97)$ \\
\hline Single parent & $2(3)$ \\
\hline \multicolumn{2}{|c|}{ Table 3. The Demographic Characteristics of the Parents } \\
\hline Variables & $\mathrm{n}(\%)$ \\
\hline \multicolumn{2}{|l|}{ Mother's age } \\
\hline$<30$ yrs & $18(26.5)$ \\
\hline $30-35$ yrs. & $40(58.8)$ \\
\hline$>35$ yrs. & $10(14.7)$ \\
\hline \multicolumn{2}{|l|}{ Mother's occupational status } \\
\hline Employed & $6(8.8)$ \\
\hline Housewife & $62(91.2)$ \\
\hline \multicolumn{2}{|l|}{ Mother's education level } \\
\hline$<$ high school & $29(42.6)$ \\
\hline High school & $26(38.2)$ \\
\hline College/university education & $13(19.2)$ \\
\hline \multicolumn{2}{|l|}{ Father's age } \\
\hline$<30$ yrs & $12(17.9)$ \\
\hline $30-35$ yrs. & $30(44.8)$ \\
\hline$>35$ yrs. & $25(37.3)$ \\
\hline \multicolumn{2}{|l|}{ Father's occupational status } \\
\hline Employed & $60(89.6)$ \\
\hline Unemployed & $7(10.4)$ \\
\hline \multicolumn{2}{|l|}{ Father's education level } \\
\hline$<$ high school & $30(44.8)$ \\
\hline High school & $28(41.8)$ \\
\hline College/university education & $9(13.4)$ \\
\hline \multicolumn{2}{|l|}{ Marital status of the parents } \\
\hline Married & $64(94.2)$ \\
\hline Divorced/Widowed & $2(2.9)$ \\
\hline Re-married & $2(2.9)$ \\
\hline \multicolumn{2}{|l|}{ Mental disorder in parents } \\
\hline Yes & $6(8.8)$ \\
\hline No & $62(91.2)$ \\
\hline
\end{tabular}

Evaluation of child abuse showed that 60 children had experienced at least 1 type of emotional abuse, out of which $8(11.8 \%)$ experienced one, 16 (23.5\%) experienced $2-3$, and $36(52.9 \%)$ experienced 4 or more types of emotional abuse.

A total of 34 children (50\%) reported at least 1 type of physical abuse, among which $12(17.6 \%)$ reported one, $15(22.1 \%) 2-3$, and $7(10.3 \%)$ reported 4 or more types of physical abuse. One child (1.5\%) had experienced sexual abuse.

The frequency of comorbidity of physical and emotional abuse at the onset of the study was 34 cases $(50 \%)$, which dropped to 2 cases $(2.9 \%)$ in the first assessment (at 3 months), and to $1(1.5 \%)$ in the second assessment (at 6 months).

Data obtained from the Child's Strengths and Difficulties Questionnaire were analyzed using repeated measures ANOVA. The results revealed that after controlling mother's education, except emotional symptoms and socialization subscales, in others the differences between the first and second and the first and third assessments were statistically significant (Table 4). Thus, evaluating the differences between the mean values in the 3 levels revealed a significant reduction in the mental health score of the mothers $(p=0.001)$.

Evaluating the changes in child abuse during the interventions using Friedman test indicated that the mean score of physical abuse and emotional abuse during the 3 levels of intervention significantly decreased $(p<0.001$; Table 5$)$.

\section{Discussion}

Evaluation of the efficacy of interventions for reducing most of behavioral problems of children in our study revealed that the intervention program successfully decreased the severity of the problems. In addition, this finding confirms the possible efficacy of family behavioral interventions for decreasing the behavioral and emotional problems of children (38). In another study (39), it was demonstrated that intervention among high risk families increased the productivity of children and resolved their behavioral problems. It could not be clearly specified that whether targeting the parenting style of parents resolved children's problems, or promoting the mental health of parents decreased their negative perception about their children's behavior. Harnett and Dawe (39) believed that

Table 4. ANOVA With Repeated Measures for the Mean Scores of SDQ in Children and GHQ in Mothers in Pre-intervention, 3 , and 6 months Postintervention

\begin{tabular}{|c|c|c|c|c|c|}
\hline & & Mean (SD) & & $\mathrm{F}$ & $\mathrm{p}$ \\
\hline & Before the intervention & $3^{\text {rd }}$ month follow-up & $6^{\text {th }}$ month follow-up & & \\
\hline \multicolumn{6}{|c|}{ Children's Strengths and Difficulties } \\
\hline Emotional symptoms & $8.47(1.99)$ & $8.10(1.68)$ & $7.73(1.51)$ & $0.44^{\mathrm{a}}$ & 0.64 \\
\hline Conduct problem & $9.43(3.00)$ & $8.36(1.24)$ & $7.19(0.71)$ & 4.61 & 0.014 \\
\hline Hyperactivity & $10.25(1.88)$ & $11.13(1.66)$ & $10.79(1.21)$ & 5.12 & 0.009 \\
\hline Peer problems & $7.25(1.22)$ & $7.09(1.36)$ & $6.29(1.29)$ & 3.63 & 0.033 \\
\hline Socialization & $12.90(1.54)$ & $12.62(1.59)$ & $12.93(1.39)$ & 0.03 & 0.97 \\
\hline Mental Health (GHQ score) & $27.15(14.12)$ & $22.08(13.38)$ & $17.58(8.07)$ & 7.86 & $0.001^{\mathrm{a}}$ \\
\hline \multicolumn{6}{|l|}{${ }^{a}$ Controlling for Mother education } \\
\hline \multirow[t]{2}{*}{ Variable } & & Mean Rank & & \multirow{2}{*}{ Chi square } & \multirow{2}{*}{$\mathrm{p}$} \\
\hline & Before the intervention & $3^{\text {rd }}$ month follow-up & $6^{\text {th }}$ month follow-up & & \\
\hline Physical abuse & 2.50 & 1.76 & 1.74 & 67.36 & 0.001 \\
\hline Emotional abuse & 2.86 & 1.65 & 1.49 & 104.29 & 0.001 \\
\hline
\end{tabular}


empowering parents with emotional adjustment leads to better management of children and teaching child management skills to parents improves their emotional efficiency.

In our study, the results of GHQ-28 questionnaire revealed that more than one-third of parents $(33.8 \%)$ had a score higher than the cut-off point before the intervention; this value significantly decreased at 6 months $(7.4 \%)$. The study results also showed that the mean rank of emotional and physical abuse during the intervention significantly decreased and this reduction for physical abuse was more significant than the emotional abuse.

Mikton and Butchart (40) in their systematic review on interventions done for child abuse, reported that providing education of parents and multi-level programs are more effective for preventing child abuse. Our study as a multilevel intervention, targeted multiple problems and requirements of families by providing medical, psychological, psychiatric, and educational services. Moreover, our study was a family wellness program offering interventions from short-term counseling to parenting classes and, sometimes, home visits for children at risk of abuse (41). These programs are a series of designed services, thus, separate assessment of their individual efficacy is not possible. However, the results of meta-analyses showed that such programs decrease the rate of child abuse (42).

In our study, almost all interventions and services were provided in the psychosocial support unit. Chaffin et al. (43) found that services offered in the unit were more effective than services provided during home visits. On the other hand, those referred to the psychosocial support unit included infants and newborns presenting to the medical center for routine health care services and checkups, therefore, these interventions could be included in the health system services. Dubowitz et al. (44) demonstrated that offering these services to high risk families leads to decreased rate of abuse and severe punishment. Thus, these interventions can be added to the general health interventions. Evidence shows that these interventions, especially for potentially at risk families, significantly decrease substance abuse and related child abuse (45).

\section{Conclusion}

Based on the obtained results, it seems that the psychosocial support unit can be a suitable center to provide services for abused children and their families. Although the service package used in our study limited separate evaluation of the efficacy of interventions, it contained all the various required services by the families. A multidisciplinary team is required for providing such services. Moreover, in these interventions, family is considered as a single unit, and in some cases, family members significantly help and participate in the services.

\section{Limitations}

Our study had some limitations. The first was that interventions were offered in a service package, thus, we could not separately assess the effectiveness of each intervention. For example, we could not specify whether education of parenting styles to parents helped improve children's problems, or promoting the mental health of parents decreased their negative perception about their children's behaviors. The second limitation of our study similar to others (46) was that the participating families had high rate of tension and resistance, which is a common problem in child abuse studies. Abusive and high risk families are usually not willing to participate in interventional programs and are less likely to enroll in research-based programs (47). Another limitation was the duration of followup of the patients, which was 6 months in our study. It seems that this time was not enough to confirm the continuous efficacy of interventions and could be a limitation for ensuring the stability of results and outcome of this interventional package (39).

Another limitation of the current study was that a psychologist filled out the questionnaires. The main reason for this was further scrutiny and higher accuracy when collecting the data because filling out the questionnaires by the mothers carried the risk of distortion of information. To prevent bias when collecting the data, the mentioned psychologist only had the task to filling out the questionnaire and played no role in providing services. However, it is still considered a limitation of this study.

Absence of a control group was a major limitation of this study. However, we could not design a control group because it was unethical to deprive a group of patients from receiving adequate care. Thus, it was considered as a limitation of this study, and only patients' information was compared before and after the intervention.

\section{Acknowledgements}

This study was supported by a grant from Hormozgan University of Medical Sciences (Number: 24/p/10276). We also wish to thank the staff of pediatric hospital in Bandar Abbas, Iran, for their collaboration in the study. All the findings, conclusions, and recommendations expressed in this manuscript are those of the authors and do not necessarily reflect the views of the Medical University.

\section{Conflict of Interests}

The authors declare that they have no competing interests.

\section{References}

1. Miri S, Ameri GF, Alizadeh SM, Froodnia F. Prevalence of child abuse in high school students of Bam city (Kerman. Iran) in 2003. Journal of Kerman University of Medical Sciences. 2006;13(1):43-50.

2. Vizeh O, Moradi S, Fadaee Z, Habibi AsgharAbad M. A comparative study of the prevalence of child abuse in highschools based on gender, education and history of divorce in the family. J Family Res. 2008;4(2):145-65.

3. Bronfenbrenner U. Contexts of child rearing: Problems and prospects. Am Psychol. 1979;34(10):844.

4. Bronfenbrenner U. Ecology of the family as a context for human development: Research perspectives. Dev Psychol. 1986;22(6):723.

5. Garbarino J, Barry F. The community context of child abuse and neglect. Understanding abusive families: An ecological approach to theory and practice. San Francisco: Jossey-Bass.1997:56-85.

6. Bronfenbrenner U, Morris PA. Handbook of child psychology 5th ed. Damon W, Lerner R, editors. New York: John Wiley \& Sons; 1998.

7. Windham AM, Rosenberg L, Fuddy L, McFarlane E, Sia C, Duggan AK. Risk of mother-reported child abuse in the first 3 years of life. 
Child Abuse Negl. 2004;28(6):645-67.

8. Kolko DJ. characteristics of child Victims of physical violence Research findings and clinical implications. J Interpers Violence. 1992;7(2):244-76

9. Rogosch FA, Cicchetti D, Aber JL. The role of child maltreatment in early deviations in cognitive and affective processing abilities and later peer relationship problems. Dev Psychopathol. 1995;7(04):591-609.

10. Shields A, Cicchetti D. Reactive aggression among maltreated children: The contributions of attention and emotion dysregulation. J Clin Child Psychol. 1998;27(4):381-95.

11. DePanfilis D, Zuravin SJ. Predicting child maltreatment recurrences during treatment. Child Abuse Negl. 1999;23(8):729-43.

12. Cicchetti D, Toth SL, editors. Developmental processes in maltreated children. 46th Annual Nebraska Symposium on Motivation, 1998, Lincoln, NE, US; 2000. University of Nebraska Press.

13. Fluke J, McDonald WR. Rereporting and Recurrence of Child Maltreatment: Findings from NCANDS. US Department of Health and Human Services, Office of the Assistant Secretary for Planning and Evaluation Washington, DC; 2005.

14. Fuller TL. Child safety at reunification: A case-control study of maltreatment recurrence following return home from substitute care. Child Youth Serv Rev. 2005;27(12):1293-306.

15. Jackson S, Thompson RA, Christiansen EH, Colman RA, Wyatt J, Buckendahl CW, et al. Predicting abuse-prone parental attitudes and discipline practices in a nationally representative sample. Child Abuse Negl. 1999;23(1):15-29.

16. Black DA, Heyman RE, Slep AMS. Risk factors for child physical abuse. Aggression and Violent Behavior. 2001;6(2):121-88.

17. Chaffin M, Kelleher K, Hollenberg J. Onset of physical abuse and neglect: Psychiatric, substance abuse, and social risk factors from prospective community data. Child abuse \& neglect. 1996;20(3):191203.

18. Berger LM, Brooks-Gunn J. Socioeconomic Status, Parenting Knowledge and Behaviors, and Perceived Maltreatment of Young Low-Birth-Weight Children. Social Service Review. 2005;79(2):23767.

19. Sidebotham P, Golding J, Team AS. Child maltreatment in the "Children of the Nineties": A longitudinal study of parental risk factors. Child abuse \& neglect. 2001;25(9):1177-200.

20. Walsh C, MacMillan HL, Jamieson E. The relationship between parental substance abuse and child maltreatment: findings from the Ontario Health Supplement. Child abuse \& neglect. 2003;27(12):140925 .

21. Coohey C. Physically abusive fathers and risk assessment. Child Abuse \& Neglect. 2006;30(5):467-80.

22. Connell CM, Bergeron N, Katz KH, Saunders L, Tebes JK. Rereferral to child protective services: The influence of child, family, and case characteristics on risk status. Child Abuse \& Neglect. 2007;31(5):573-88.

23. Dubowitz H, Kim J, Black MM, Weisbart C, Semiatin J, Magder LS. Identifying children at high risk for a child maltreatment report. Child abuse \& neglect. 2011;35(2):96-104.

24. Deccio G, Horner WC, Wilson D. High-risk neighborhoods and high-risk families: Replication research related to the human ecology of child maltreatment. Journal of Social Service Research. 1994;18(34):123-37.

25. Ernst JS. Community-level factors and child maltreatment in a suburban county. Social Work Research. 2001;25(3):133-42.

26. Coulton CJ, Crampton DS, Irwin M, Spilsbury JC, Korbin JE. How neighborhoods influence child maltreatment: A review of the literature and alternative pathways. Child abuse \& neglect. 2007;31(11):111742.

27. Turner KM, Sanders MR. Dissemination of evidence-based parenting and family support strategies: Learning from the Triple P-Positive Parenting Program system approach. Aggression and Violent Behavior. 2006;11(2):176-93.

28. Azar ST. A cognitive behavioral approach to understanding and treating parents who physically abuse their children. Child abuse: New directions in prevention and treatment across the lifespan. 1997;4:79101

29. King PA, Chalk R. Violence in families: Assessing prevention and treatment programs. National Academies Press; 1998.

30. Sanders M, Cann W. Promoting positive parenting as an abuse prevention strategy. Browne K, Hanks H, Stratton P, Hamilton C, editors. Chichester, England: Wiley and Sons; 2002.
31. Moran P, Ghate D. The effectiveness of parenting support. Children \& Society. 2005;19(4):329-36.

32. Harder J. Prevention of child abuse and neglect: An evaluation of a home visitation parent aide program using recidivism data. Research on Social Work Practice. 2005;15(4):246-56.

33. McCurdy K. The influence of support and stress on maternal attitudes. Child abuse \& neglect. 2005;29(3):251-68.

34. Lundahl BW, Nimer J, Parsons B. Preventing child abuse: A metaanalysis of parent training programs. Research on Social Work Practice. 2006;16(3):251-62.

35. Arabgol F, Derakhshanpour F, Panaghi L, Sarjami S, Hajebi A. Effect of Therapeutic Interventions on Behavioral Problems of Abused Children. Iranian Journal of Psychiatry and Clinical Psychology. 2014;19(3):202-10.

36. Goodman R. The Strengths and Difficulties Questionnaire: a research note. Journal of child psychology and psychiatry. 1997;38(5):581-6.

37. Goodman R. Psychometric properties of the strengths and difficulties questionnaire. Journal of the American Academy of Child \& Adolescent Psychiatry. 2001;40(11):1337-45.

38. Tehranidoost M, Shahrivar M, Pakbaz B, Rezaie A, Ahmadi F. Validity of Farsi Version of Strengths and Difficulties Questionnaire (SDQ). 2007;8(4).

39. Harnett PH, Dawe S. Reducing child abuse potential in families identified by social services: Implications for assessment and treatment. Brief treatment and crisis intervention. 2008;8(3):226.

40. Mikton C, Butchart A. Child maltreatment prevention: a systematic review of reviews. Bulletin of the World Health Organization. 2009;87(5):353-61.

41. Palusci VJ, Haney ML. Strategies to prevent child maltreatment and integration into practice. APSAC Advisor. 2010;22(1):8-17.

42. MacLeod J, Nelson G. Programs for the promotion of family wellness and the prevention of child maltreatment: A meta-analytic review. Child abuse \& neglect. 2000;24(9):1127-49.

43. Chaffin M, Silovsky JF, Funderburk B, Valle LA, Brestan EV, Balachova T, et al. Parent-child interaction therapy with physically abusive parents: efficacy for reducing future abuse reports. Journal of consulting and clinical psychology. 2004;72(3):500.

44. Dubowitz H, Feigelman S, Lane W, Kim J. Pediatric primary care to help prevent child maltreatment: the Safe Environment for Every Kid (SEEK) model. Pediatrics. 2009;123(3):858-64.

45. Ondersma S, Chase S. Substance abuse and child maltreatment prevention. APSAC Advisor. 2003;15(3):8-11.

46. Hansen DJ, Warner-Rogers JE, Hecht DB. Implementing and evaluating an individualized behavioral intervention program for maltreating families. Handbook of child abuse research and treatment: Springer; 1998. p. 133-58.

47. Lutzker JR, Tymchuk AJ, Bigelow KM. Applied research in child maltreatment: Practicalities and pitfalls. Children's Services: Social Policy, Research, and Practice. 2001;4(3):141-56. 